\title{
HERBS - ARE THEY SAFE?
}

\section{S. Radhika}

Traditional herbal medicines are getting significant attention in global health debates. China, India, Nigeria, America and WHO have all made substantial research investments in traditional herbal medicines. As herbal medicine is potentially contributing to the advancement of healthcare, like the artemisinins isolated from Artemisia annua, and contributing to increased utilization for self-medication by patients, it is imperative to emphasize in thepresent context, that inappropriate use of traditional medicines and practices can have negative or dangerous effects. However, significant toxicity usually is a result of suicide attempt or inappropriate self-administration for the therapeutic purposes.

A consumer poll in US in 1998 indicated that one-third of respondents use botanical remedies, and nearly one in five taking prescription medications also used herbs, high-dose dietary supplements or both. An estimated 15 million adults are at risk for potential adverse interactions involving prescription medications and herbs or vitamin supplements.

Self-medication by patients is increasing, as they believe that herbal remedies are safe and have no side effects, unlike modern medicine. However, the general perception that herbal remedies or drugs are very safe and devoid of adverse effects is not only untrue but also misleading.

Herbs have been shown to be capable of producing a wide range of undesirable or adverse reactions some of which are capable of causing serious injuries, lifethreatening conditions, and even death. Numerous and irrefutable cases of poisoning have been reported in the literature.

Cardiac glycosides found in a diverse group of plants including Digitalis purpurea and Digitalis lanata(foxgloves), Nerium oleander (common oleander), Thevetia peruviana (yellow oleander), Convallaria

Article received on 01 APR 2017, published on 31APR 2017 S. Radhika ${ }^{1}$

Associate Professor, Department of Clinical Pharmacology \& Therapeutics, NIMS, India.

Corresponding Author: S. Radhika

Email: dr_radhika_s@yahoo.co.in majalis (lily of the valley), Urginea maritima and Urginea indica (squill), Strophanthus gratus (ouabain), Apocynum cannabinum (dogbane), and Cheiranthus cheiri (wallflower), primarily affect cardiovascular, neurologic, and gastrointestinal systems. The pathophysiology that produces cardiotoxicity involves prolonging refractory period in atrioventricular node, shortening refractory periods in atria and ventricles, and decreasing resting membrane potential. Sinus bradycardia is the most frequent cardiovascular sign, and it may progress to atrioventricular block and asystole. One such unusual case of poisoning with Cryptostegia Grandiflora (rubber vine) has been reported in this issue, who presented with bradycardia and was diagnosed to be herb-induced cardiotoxicity. Cryptostegia species contains significant quantities of cardenolides digitoxigenin, which is cardiotoxic.

Herb "Ma Huang" (Ephedra) is traditionally used in China to treat respiratory congestion. In the United States, the herb was marketed as a dietary aid, and it's overdosage led to at least a dozen deaths, heart attacks and strokes.

In UK and many other countries, Aristolochia fangchi was linked to the development of subacute interstitial fibrosis of the kidney referred to as "Chinese herbs nephropathy".

Misidentification of medicinal plants and mislabeling herbal medicinal products are sometimes responsible for some of the observed adverse events, for instance, in Belgium, at least 70 people required renal transplant or dialysis for interstitial fibrosis of the kidney after taking a herbal preparation made from the wrong species of plant as slimming treatment.

Poisoning due to homemade medicated liquor containing aconite and traditional medicine containing A. Carmichael were reported in China between 1999 and 2008. Severe cases of cardiac toxicity from consumption of aconitine-containing herbal preparation manifesting as ventricular tachycardia and fibrillation and eventually leading to death have been reported.

In terms of population exposure alone, it is essential to identify the risks associated with the use of herbal medicines, and in this regard, the safety of these 
products has become an issue of great public health importance.

\section{REFERENCES:}

1. Valli G and Giardina EGV. Benefits, Adverse Effects and Drug Interactions of Herbal Therapies with Cardiovascular Effects. J Am Coll Cardiol 2002; 39:108395.

2. Tilburt JC, Kaptchuk TJ. Herbal medicine research and global health: an ethical analysis. Bulletin of the World Health Organization. http://www.who.int/bulletin/ volumes/86/8/07-042820/ en/
3. Traditional Medicine. http://www. who.int/ media centre/factsheets/2003/fs134/en/

4. Ekor M. The growing use of herbal medicines: issues relating to adverse reactions and challenges in monitoring safety. Frontiers in Pharmacology. 2013;4:177.

5. Radenkova-Saeva J and Atanasov P. CARDIAC GLYCOSIDE PLANTS SELF-POISONING. Acta Medica Bulgarica, Vol. XLI, 2014, № 1:99-104.

6. Cryptostegia. In: Anthony $\mathrm{P}$ Knight. A guide to poisonous house garden plants:Teton New Media Publishers. 2007. p. 92. 